\title{
ESTADO, MODERNIDADE, GLOBALIZAÇÃO E CRISE: OS TRATADOS INTERNACIONAIS E AS TRANSFORMAÇÕES JURÍDICAS NA REGULAÇÃO DOS CONHECIMENTOS TRADICIONAIS
}

\section{STATE, MODERNITY, GLOBALIZATION AND CRISIS: THE INTERNATIONAL TREATIES AND LEGAL CHANGES IN REGULATION OF TRADICIONAL KNOWLEDGE}

\author{
${ }^{1}$ Luciano Moura Maciel
}

\section{RESUMO}

As concepções de ordenação jurídica do Estado e da Modernidade estão em crise, diante do processo de globalização, inclusive do Direito. O artigo objetiva analisar as transformações jurídicas dos conhecimentos tradicionais a partir da promulgação da Lei 13.123/2015 sobre a regulação do acesso e repartição de benefícios dos conhecimentos tradicionais na relação entre Estado em crise, por um lado, e por outro o fortalecimento dos marcos normativos internacionais emanados de uma ordem global exógena ao Estado nacional brasileiro. A metodologia da pesquisa é qualitativa, visando ao fim analisar criticamente as alterações legislativas sobre os conhecimentos tradicionais associados à biodiversidade.

Palavras-chave: Estado, Modernidade, Globalização, Conhecimentos tradicionais

\begin{abstract}
The conceptions of the state and modernity are in crisis, facing the globalization process, including the right. The article aims to analyze the legal transformation of traditional knowledge from the enactment of Law 13.123/2015 on the regulation of access and benefit sharing of traditional knowledge in the relationship between the state in crisis, on the one hand, and on the other the strengthening of legal frameworks International originating from an exogenous global order to the Brazilian national state. The research methodology is qualitative, aiming to finish critically analyze the legislative changes on the traditional knowledge associated with biodiversity.
\end{abstract}

Keywords: State, Modernity, Globalization, Traditional knowledge

\footnotetext{
${ }^{1}$ Doutorado em Direito pela Universidade Federal do Pará - UFPA, Brasil. Professor pela Universidade do Estado do Amazonas - UEA, Amazonas (Brasil). E-mail: advlucianomoura@gmail.com
} 


\section{Introdução}

O presente artigo tem por objetivo analisar as transformações jurídicas dos conhecimentos tradicionais no contexto do "Estado de crise" ligado à crise da Modernidade. Para conceituar o "Estado de crise" o texto busca dialogar com Zygmung Bauman, Carlos Bordoni e Bresser Pereira, para refletir sobre a Modernidade nos auxiliou Boaventura de Souza Santos, Mignolo e Quijano.

As transformações jurídicas referem-se à promulgação da Lei 13.123, de 20 de maio de 2015, lei ordinária federal que visa regular o acesso ao patrimônio genético sobre a proteção e o acesso ao conhecimento tradicional associado e sobre a repartição de benefícios para a conservação e uso sustentável da biodiversidade.

A nova legislação modificou a regulação dos conhecimentos tradicionais provocando uma série de divergências com os Tratados Internacionais sobre conhecimentos tradicionais e repartição de benefícios, quais sejam: a Convenção sobre a Diversidade Biológica, assinado pelo Brasil 04 de junho de 1992, no Rio de Janeiro, promulgado no direito interno pelo Decreto 2.519, em 16 de março de 1998 e o Protocolo de Nagoya assinado, mas ainda não ratificado pelo Brasil.

O método de pesquisa utilizado é qualitativo por visar compreender e analisar os conhecimentos tradicionais em uma problemática mais ampla envolvendo a crise do Estado, da Modernidade e refletir sobre a influência da globalização na regulação dos conhecimentos tradicionais voltadas a beneficiar o livre mercado, desregulando e privatizando os conhecimentos tradicionais e flexibilizando os direitos dos povos, comunidades e agricultores familiares. Neste sentido, a pesquisa utilizou de obras bibliográficas, artigos científicos, legislação dos Tratados Internacionais e o texto da Lei $13.123 / 2015$, juntamente com sua exposição de motivos para analisar o processo de desburocratização das políticas de acesso aos conhecimentos tradicionais.

No intuito de cumprir com as reflexões traçadas este trabalho é composto de três tópicos. No primeiro discute-se o Estado de crise e a crise da Modernidade, situando as razões da perda de poder do Estado para as corporações transnacionais e demonstrando a origem desta crise: o esgotamento do paradigma de Estado e Direito Modernos.

No segundo tópico, busca-se situar uma das razões da crise do direito e da necessidade de reformulação de suas bases, estuda-se a globalização do direito, especialmente do direito ambiental, em um processo de unificação das legislações 
ambientais especialmente nos países latinos para facilitar a continuação dos processos de colonização. Para demonstrar este processo, analisaremos brevemente dois tratados internacionais, quais sejam: a Convenção sob a Diversidade Biológica e o Protocolo de Nagoya.

$\mathrm{Na}$ última parte, o artigo, sem pretender esgotar o assunto, discute-se alguns elementos de regulação da Lei 13.123/2015 e seus atritos com as normas internacionais em um processo do que chamo de "aprofundamento da mercantilização dos conhecimentos tradicionais".

\section{ESTADO EM CRISE E CRISE DA MODERNIDADE}

A palavra crise vem do latim KRISIS que significa "julgamento", "seleção", "resultado de uma avaliação", "decisão" (segundo Tucídides), mas também “contenda"

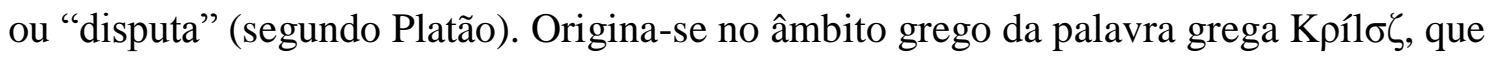
significa "juízo", "ponto crítico", mas também "habilidade para discernir", bem como “crucial”, “decisivo", relacionado à arte de julgar. (BAUMAN; BORDONI, p.09, 2016)

No Brasil, a palavra tem sido muito utilizada por jornais e revistas para caracterizar "crise econômica" que pode ser caracteriza como redução de investimentos públicos e privados, aumento do desemprego, aumento de preços, queda da demanda, características decorrentes não apenas da "crise política", mas associada ao contexto internacional que tem se transformado nas últimas três décadas. A partir da década de 80, o mundo passou por transformações em que houve a queda do Welfare State (Estado de bem-estar social) keynesiano, em uma crise global denominada por Hobsbawn (1995, p.393) de “décadas de crise”, pois os países periféricos foram fortemente influenciados pelas políticas de incentivo ao livre mercado de Reagan e Bush nos E.U.A e Margaret Thatcher na Inglaterra e pelo consenso de Washington ${ }^{3}$ passaram a estimular

\footnotetext{
${ }_{1}^{1}$ In http://origemdapalavra.com.br/site/palavras/crise/ Acesso em 24.03.2016

2 A crise política no qual estamos vivendo não é algo novo. O Constitucionalista Paulo Bonavides escreveu sobre "Crise Política" em 1978 e vários autores relacionando com a questão agrária, com violência policial, com a crise pós-regime de 1964. Para maiores detalhes ver BONAVIDES, Paulo. A crise política brasileira, Editora Forense, Rio, Editora Forense, 1969; 2. ed.: 1978.

${ }^{3} \mathrm{O}$ consenso de Washington explica Pereira (1991) formou-se a partir da crise do consenso Keynesiano e da crise do desenvolvimento econômica elaborada na década de 40 e 50. Esta perspectiva é influenciada pelo surgimento da nova direito, neoliberal, a partir das contribuições da Escola Austríaca (Hayek e Von Misses), dos monetaristas (Fridman, Johnson). Estas visões teóricas pragmáticas é própria dos economistas que trabalham nas grandes burocracias internacionais e partilhada pelas agências multilaterais em Washington, o Tesouro, o FED, o departamento dos E.U.A, os países do G-7 e os presidentes dos 20 maiores bancos internacionais constantemente ouvidos naquela capital. Esta
} 
a hegemonia neoliberal caracterizada por desregulação e liberalização dos mercados nacionais e internacionais (financeiros, de bens e fatores de produção), redução substancial do tamanho do Estado, de suas responsabilidades sociais, privatização de empresas estatais e dos serviços públicos (ALMEIDA, 1997, p.177).

O Brasil e a América Latina no final da década de 80 e início da década de 90 passavam por uma crise histórica marcada por estagnação econômica e altas taxas de inflação ${ }^{4}$, para o consenso de Washington as causas da crise seriam: a) excessivo crescimento do Estado, excesso de regulação e empresas estatais ineficientes; b) populismo econômico pela incapacidade de controlar o déficit público. As economias brasileiras e latino-americanas deveriam estabilizar-se por intermédio do ajuste fiscal e adoção de políticas econômicas conservadoras, em que o mercado desempenhe o papel fundamental, liberalizando-as e privatizando as empresas públicas e os bens públicos. Consequentemente, este processo acarretará no avanço do capital sobre a biodiversidade com a privatização os bens ambientais, da biodiversidade e dos conhecimentos tradicionais. ${ }^{5}$

A crise do Estado diretamente relacionada à crise econômica internacional é diferente da primeira grande crise da modernidade, a de 1929, que causou o colapso da bolsa de valores, tendo sido solucionada com a adoção das teorias econômicas de Keynes, em que o Estado deveria intervir na economia e no mercado, não apenas no viés regulação, mas promoção das políticas sociais.

Iniciou-se no pós-segunda guerra mundial, um período de reconstrução da Europa denominado por Hobsbawn (1995) de "décadas de ouro", com investimento do Estado em obras públicas de infraestrutura, planos industriais foram formulados, assistência previdenciária e políticas sociais foram marcas do período da década de 40 a meados de 70. Contudo, a crise atual é diversa. Os países afetados pela crise estão endividados, inclusive o Brasil, em que o Governo Federal solicita ao Congresso

abordagem exerceu nas décadas de 80 e 90 profunda influência nos governos e nas elites da América Latina, havendo pouca alteração do cenário no século XXI.

${ }^{4}$ Relata Pereira (1991) que países como Bolívia (1985), Peru (1988/1990), Argentina (1989/1990) e Brasil (1990) a inflação ultrapassou 50\% ao mês. Crise na América Latina: Consenso de Washington ou crise fiscal? Revista Pesquisa de Planejamento Econômica. Disponível em: http://ppe.ipea.gov.br/index.php/ppe/article/viewFile/883/820. Acesso em 25.03.2016.

5 Neste sentido, têm sido criadas Leis ambientais no Brasil e na América Latina possibilitando a concessão de áreas para exploração florestal, vide o novo código florestal, Lei 12.621/2012 e a nova lei de regulação da biodiversidade e dos conhecimentos tradicionais, Lei 13.123/2015, objeto de estudo no capítulo 3 . 
Nacional autorização para encerrar o ano com um déficit primário de $96,7 \%$ bilhões. $^{6}$ Os países envolvidos na crise internacional fazem cortes aleatórios, com poucos instrumentos para investir, situação que pode gerar mais recessão com impacto negativo aos cidadãos. (BAUMAN; BORDONI, 2016, p. 10).

Os Estados seguidores do consenso de Washington sucumbem às consequências deste modelo enfraquecedor de Estados-nacionais da Europa, América Latina e Estados Unidos. Diante das hodiernas dificuldades enfrentadas principalmente pelos países do capitalismo periférico, as empresas privadas não têm interesse em investir em Estados, em crise política e econômica pela redução do crédito bancário e por reduzidos retornos econômicos devido à redução do consumo ao lado dos fantasmas da inflação e da baixa qualificação profissional em países emergentes.

A crise do Estado contemporâneo tem sido caracterizada pelos processos de “desregulamentação", "privatização", "subsidiarização" que nas últimas três décadas vieram a substituir regulamentação, nacionalização e empreendimentos comunais. As funções do Estado têm sido deslocadas, "transferidas" e "terceirizadas" para o mercado, espaço apolítico, capturado por forças supra estatais denominada por Manuel Castells (1999) de "espaços de fluxos" politicamente e juridicamente incontroláveis, convertendo no que Bauman (2016, p.22) denomina de "estatismo sem estado", onde o Estado tenta agir no domínio da politica em constante crise, mas sem poder ou com pouco poder, na tentativa de resolver problemas locais que são globais, já que as decisões importantes ligadas ao meio ambiente e a economia mundial, são tomadas por poderes supranacionais, como as agências internacionais que definem conhecimentos tradicionais e não são instadas a observar práticas locais e consuetudinárias sobre os mesmos, aspecto a ser detalhado no segundo capítulo.

O Estado em crise representa o esgotamento de um paradigma político, jurídico e cultural denominado de Modernidade. A Modernidade ocidental é concebida por Santos (2008, p.31) como um paradigma social e cultural que se constitui a partir do século XVI e se consolida entre finais do século XVIII e meados do século XIX, assentada na regulação social que assentada na Europa em três pilares: o Estado entidade central e monopolizadora da produção de normas jurídicas; o mercado e a comunidade. Estes pilares causaram uma enorme violência histórica nas colônias em que viviam diversos povos, causando a (des) regulação colonial, pois o Estado era

6 Notícia em 25.03.2016 no sítio http://agenciabrasil.ebc.com.br/economia/noticia/2016-03/governoenvia-projeto-para-encerrar-ano-com-deficit-primario-de-r-967 Acesso em 25.03.2016. 
estrangeiro, o mercado incluía os escravos como mercadoria, e as comunidades foram arrasadas em nome do capitalismo e da missão civilizadora.

Para Dussel (1993, p. 09) a Modernidade tem início um século antes, em 1492, quando da chegada dos Europeus na América, para o autor a modernidade nasceu quando o Europeu pôde encontrar o seu "outro", controla-lo, vencê-lo e violentá-lo. O "outro", ou seja, o não Europeu, não foi descoberto, mas "encoberto"7 pela Modernidade. O autor Argentino traz a Modernidade da perspectiva da América Latina, já que foi a primeira periferia da América, em que a Europa nada teria que aprender com os novos mundos, as novas culturas, caracterizando, assim, o Eurocentrismo, já que a Europa, especialmente o Norte teria assim direito absoluto sobre os "outros" povos colonizados. (DUSSEL, 1993).

Santos (2008, p. 26) caracteriza o paradigma da Modernidade fundamentado nas ideias de diferenciação entre sujeito/objeto; entre natureza e sociedade ou cultura; redução da complexidade do mundo a leis simples para reger relações e assuntos complexos; uma separação absoluta entre o conhecimento científico considerado o único válido hierarquicamente superior aos conhecimentos tradicionais ou do senso comum e a centralidade na modificação da natureza pela ciência para apropriá-la e transformá-la em produto mercantilizável.

O paradigma Moderno acima fora utilizado pelo Direito para ocultar e invisibilizar os povos tradicionais e seus conhecimentos, assumindo o direito moderno seu viés colonial baseado na recusa do conhecimento do outro como igual e na sua conversão em objeto, legitimando a violência e a opressão das sociedades colonizadas, o que podemos denominar de colonialismo da Modernidade, movimento impensável sem o capitalismo (SANTOS, 2008), no qual a ciência moderna tem estado a serviço, consolidando a hierarquia epistemológica do conhecimento científico. Assim, o colonialismo como relação social e jurídica manteve-se ao colonialismo como dependência política de um Estado metropolitano (SANTOS, 2008 p. 32).

Mignolo (2005, p. 36) concebe colonialidade como o lado "escuro", ou seja, o outro lado da modernidade, ao referir-se no século XVI, a emergência comercial do Atlântico, como essencial a história do capitalismo e a modernidade/colonialidade. Segundo Mignolo (2005, p.36) capitalismo enquanto modernidade forma a

\footnotetext{
${ }^{7}$ Outro fator histórico do nascimento da Modernidade para Dussel (1993) foi a expulsão dos mouros, mulçumanos de Granada, Espanha em 06 de janeiro de 1492.
} 
colonialidade do poder (Quijano, 1997; 1998) que apareceu inicialmente como fenômeno europeu, do qual o não-europeu é partícipe, mas com distintas posições de poder, sendo a colonialidade o eixo que organizou a periferia como natureza apropriável.

A passagem do texto de Quijano e Wallerstein (1992: 449) oferece uma noção para compreender o sistema mundo moderno a partir do século XVI, no sentido de que a criação geopolítica da América foi um ato constitutivo do mundo moderno, sem a qual não poderia haver economia mundial capitalista. Com o processo de colonização nas Américas e a expansão do circuito comercial do Atlântico houve uma aceleração da economia capitalista, não sendo possível conceber modernidade sem colonialidade (MIGNOLO, 2005).

Assim, a colonialidade nas Américas inclusive no Brasil, fora fundamental no imaginário moderno Europeu, ocultando memórias e experiências dos escravos africanos, povos indígenas e latinos formando a diferença colonial, retratada por Bartolomé de las Casas, ${ }^{8}$ testemunha ocular da história.

A distinção entre colonialidade e colonialismo permite compreender que mesmo após a independência política das Américas e do Brasil, subsistem relações de dominação denominadas de colonialidade que foram fundamentais para a reprodução do capitalismo moderno (ASSIS, 2014).

Deste modo, reflete Santos (2008, p. 62) que é crescente o capital privado na pesquisa e no desenvolvimento tecnológico das ciências da vida e a transformação da vida em mercadoria e o conhecimento e informação sobre a vida sobre formas de capital. É preocupante o fluxo de capitais de empresas dedicadas à ciência e a tecnologia as universidades que passam a depender de financiamentos da indústria farmacêutica e de biotecnologia, que passam a definir as prioridades de pesquisa e a privatização do conhecimento pelo patenteamento (KRIMSHY, 2003).

Diante deste fluxo, faz-se mister estudarmos as normas internacionais sobre a proteção dos conhecimentos tradicionais no contexto da globalização do direito.

\footnotetext{
${ }^{8}$ Fray Bartolomé de las Casas (1484 - 1536) foi um defensor dos povos indígenas a época da colonização, defendeu os direitos humanos dos povos indígenas, reconhecendo-os como seres humanos dotados de razão e livres. Lutou pela preservação da cultura, das terras e da integridade física dos povos indígenas nas Américas. Maior aprofundamento ver GARCÍA, Emílio Garcia. Los Derechos Humanos em su origem. M. MACEIRAS y L. MENDEZ (Coordinadores). La República Dominicana y Antón de montesinos. Salamanca: Editorial San Esteban. 81-114, 2011.
} 


\section{GLOBALIZAÇÃO DO DIREITO E AS NORMAS INTERNACIONAIS SOBRE OS CONHECIMENTOS TRADICIONAIS}

A ideia de que o Direito reflete a emanação do poder soberano, independente e exclusivo do Estado, tem sido cada vez mais refratada pela influência dos processos de globalização, em que o direito encontra-se implicado, mediante a atuação de organismos internacionais multilaterais na formulação de um padrão transnacional de disciplina jurídica. (ARNAUD 1999, p. 03). A globalização segundo Beck (1999, p.27-28) não deve ser concebida de maneira monocausal, restrita ao âmbito da globalização econômica, mas de uma forma pluridimensional relativa a dimensões jurídicas, culturais, ecológicas e políticas. Assim, a globalização indica processos em que "os Estados nacionais veem a sua soberania, sua identidade, suas redes de comunicação, suas chances de poder sofrerem a interferência cruzada de atores transnacionais.” (BECK, 1999).

A globalização transformou o paradigma Westfaliano-Keynesiano ${ }^{9}$ em que as discussões de justiça social e de direito sobre um território soberano limitavam-se ao poder interno do Estado, na opinião dos liberais bastava que houvesse nesses Estados igualdade dos cidadãos perante a lei, para outros, igualdade de oportunidades e acesso de todos os cidadãos aos recursos naturais e sociais com respeito as suas necessidades de participação em nível de igualdade com os demais membros da comunidade política (FRASER, 2005). A crise atual demonstra que os paradigmas do Estado Liberal não são suficientes para a consecução dos direitos, especialmente os direitos sociais.

O direito encontra-se associado ao processo de globalização, em que as decisões jurídicas e políticas são tomadas dentro de um Estado territorial, geralmente em países centrais e tem impacto nas vidas das pessoas situadas fora deste Estado nacional (FRASER, 2005), como ocorre nas atividades das corporações internacionais, com a atuação de especuladores financeiros e de divisas internacionais, inversores institucionais, organizações supranacionais, organizações não governamentais internacionais e agências multilaterais internacionais.

\footnotetext{
${ }^{9}$ Explica Fraser (2005, p. 32) que o paradigma Westfaliano-Keynesiano de Estado refere ao período das discussões de justiça no período do Estado de Bem Estar Social pós-bélico, que vigorou em considerável parte do mundo ocidental de 1945 a fins da década de 70. A categoria Westfaliana se refere ao Tratado de Westfália de 1948 que estabeleceu alguns princípios fundamentais na relação entre os Estados modernos, no imaginário jurídico-político o mundo foi organizado em um sistema de Estados territoriais soberanos que se outorgavam reconhecimento mútuo.
} 
O Constitucionalista Garavito (2011, p.10) diante da globalização do direito e da perspectiva jurídica latino-americana de povos colonizados, destacava a importância de estudos que contribuíssem com novos ângulos de visão para o pensamento jurídico. Para o autor Colombiano a premissa da unidade do Estado, território, autoridade política e sistema jurídico interno refratário à globalização do direito não encontra mais guarida na realidade jurídica atual, em que o Estado compartilha função normativa com instituições internacionais desde Organização Mundial do Comércio, Cortes internacionais, entidades privadas e organizações não governamentais como as que participam da criação de normas empresariais, códigos de conduta das empresas transnacionais em matérias ambientais.

Deste modo, o direito pós-Westfaliano consiste em "administrar a globalização" e os Estados têm transformado seus ordenamentos jurídicos nacionais para adequarem suas normas internas ao complexo emaranhado normativo impostos pelas organizações internacionais. (Garavito, 2011; Santos, 2008). Nessa reflexão, estamos a falar em mecanismos jurídicos construídos pelas agências multilaterais que visam a traçar procedimentos e mecanismos para que os Estados juridicamente protejam os conhecimentos tradicionais.

O antropólogo Almeida (2010, p.11) tem alertado sobre as estratégias de cooperação técnico-científica internacional, das agências multilaterais oficiais, organizações nãogovernamentais, cuja forma de ação seria de viés desenvolvimentista com tendência a flexibilizar direitos territoriais dos povos indígenas e comunidades tradicionais através das conceituação unívoca de conhecimentos tradicionais ${ }^{10}$ ligado a apropriação privada e das agroestratégias. ${ }^{11}$

Os atores transnacionais que intensificam debates sobre os nos marcos regulatórios do conhecimento tradicional são as agências multilaterais como a ONU Organização das Nações Unidas, o BIRD - Banco Interamericano Mundial, a OMC Organização Mundial do Comércio e o OMPI - Organização Mundial da Propriedade intelectual. Infere Almeida (2010, p. 10-11):

\footnotetext{
${ }^{10}$ No último capítulo discorreremos sobre as conceituações normativas internacionais e nacionais dos conhecimentos tradicionais e suas limitações em relação a uma conceituação mais abrangente de conhecimentos tradicionais.

${ }^{11}$ Infere Almeida (2010, p. 09) explica que as agroestratégias significam um conjunto de iniciativas organizadas por agências multilaterais, conglomerados financeiros e entidades representativas de grandes empreendimentos agropecuários para remover os obstáculos jurídico-formais a expansão do cultivo de grãos e para acrescer novas extensões de terra aos interesses industriais, em um contexto de elevação do preço das commodities agrícolas e metálicas. Um de suas facetas é a flexibilização dos direitos territoriais indígenas, quilombolas e demais comunidades tradicionais.
} 


\begin{abstract}
Neste sentido, é que as estratégias das agencias multilaterais como a ONU, o BIRD, a OMC e a OMPI e suas intervenções face aos conhecimentos tradicionais associados à biodiversidade, podem ser classificadas dentre as medidas que convergem para o que Bourdieu designa de uma "homogeneização jurídica" (Bourdieu, 2001:107). Destaque-se que OMC, UNESCO e OMPI desenvolvem ações complementares neste propósito de unificar procedimentos de reconhecimento de saberes tradicionais que são coextensivas à "homogeneização jurídica". Tornaram-se procedimentos coextensivos à noção de propriedade intelectual.
\end{abstract}

Na região Pan-Amazônica ${ }^{12}$ verificam-se esforços de unificar os preceitos legais para padronizar a legislação de diversos países, em um processo de globalização do direito, especialmente do direito ambiental, com objetivo de atender as demandas da economia globalizada, o direito também se globaliza, indiferente aos conflitos sociais reais localizados sobre os territórios dos povos e comunidades tradicionais e as diferenças conceituais do que se entende por conhecimentos tradicionais.

Inicialmente, tem-se que a pedra fundamental sobre o acesso aos conhecimentos tradicionais foi à subscrição e ratificação pelo Brasil da Convenção sobre a Diversidade Biológica ${ }^{13}$. É um tratado internacional assinado pelo Brasil 04 de junho de 1992 no Rio de Janeiro, promulgado no direito interno pelo Decreto 2.519, em 16 de março de $1998 .{ }^{14} \mathrm{O}$ Brasil foi o primeiro país a subscrever a convenção, durante a Eco/92 (SANTILLI, 2005, p.44).

Os objetivos da Convenção constante em seu texto são de promover a conservação da diversidade biológica, a utilização sustentável de seus componentes e a repartição justa e equitativa de seus benefícios derivados da utilização dos recursos genéticos e dos conhecimentos, inovações e práticas associadas à biodiversidade detidos

\footnotetext{
12 A Pan-Amazônia envolve países como Brasil, Colômbia, Peru, Venezuela, Bolívia, as Guianas e Suriname. São países que possuem a floresta Amazônia em seu território. Diversos movimentos sociais se apropriaram deste conceito para iniciar um processo de luta diante dos problemas de avanço do capital às reservas da biodiversidade, são povos que sofrem grande pressão empresarial por minério, madeira e biodiversidade. Entrevista de Letícia Tura. In http://fase.org.br/pt/informe-se/noticias/o-sentido-da-panamazonia/\#sthash.YoS5jujz.dpuf. Acesso em 25.03.2016.

${ }^{13} \mathrm{O}$ grande discurso ideológico vigente quando da tramitação e aprovação da Convenção era o de que os países "em desenvolvimento" 13 possuidores de uma ampla gama de recursos genéticos e pouca tecnologia procuravam assegurar a soberania destes recursos, enquanto dificultavam o acesso dos países desenvolvidos. Os "países do Sul” (Santos: 2009) exigiam que os benefícios econômicos em prol dos países do Norte fossem compartilhados, sendo injusta a proteção das indústrias por meio de patentes, desta forma, estaria desprotegido os conhecimentos tradicionais e os recursos nacionais ${ }^{13}$ (WINDHAMBELLORD e COUTO; 2014; SANTILLI: 2005).

${ }^{14}$ BRASIL, Presidência da República. Decreto no 2.519, de 16 de março de 1998. Promulga a Convenção sobre a Diversidade Biológica, assinada no Rio de Janeiro, em 05 de julho de 1992, Brasília, 1998. <http://www.planalto.gov.br. >Acessado em 29.09.2011
} 
por "comunidades locais e populações indígenas com estilos de vida tradicionais" (art. $1^{\mathrm{o}} \mathrm{c} / \mathrm{c}$ art. $\left.8 \mathrm{j}\right) .{ }^{15}$

$\mathrm{Na}$ interpretação da norma "as comunidades locais" e as "populações indígenas" teriam dois direitos fundamentais: primeiro o de consentir ou não com a utilização de seus conhecimentos tradicionais associados à biodiversidade e segundo de receber parcela justa e equitativa de benefícios decorrentes da utilização dos saberes e do patrimônio genéticos pertencentes aos grupos (DOURADO, 2010, p. 86).

A CDB estabelece que para o acesso aos conhecimentos tradicionais associados ao patrimônio genético deverá haver uma harmonia com os termos mutuamente acordados, somando-se com o consentimento fundamentado. ${ }^{16}$ Por seu turno, o art. 8j da Convenção preceitua que cabe as partes promulgarem legislação nacional que respeite e preserve o conhecimento de indígenas e comunidades tradicionais que sejam relevantes para a preservação da diversidade biológica, incentivando a repartição de benefícios. (WINDHAM-BELLORD e COUTO: 2014).

Outra importante norma internacional sobre o acesso e repartição de benefícios dos conhecimentos tradicionais é o Protocolo de Nagoya sobre acesso e repartição de benefícios. Adotado em 29 de outubro de 2010, na décima reunião da Conferência das Partes na Convenção sobre a Diversidade Biológica (COP-10), celebrada em Nagoya, no Japão. O Protocolo possui natureza jurídica de tratado internacional que, para entrar em vigor, necessita da ratificação de pelo menos 50 (cinquenta) países. O Brasil assinou o Protocolo sobre Acesso a Recursos Genéticos e a Repartição Justa e Equitativa dos Benefícios advindos de sua Utilização, na sede da Organização das Nações Unidas em Nova York, no dia 02 de fevereiro de 2011. ${ }^{17}$ (MACIEL, 2012)

O Brasil, embora tenha sido um dos maiores articuladores do Tratado e um dos primeiros signatários, ainda não ratificou o Protocolo. Trata-se de um instrumento jurídico internacional com adesão de 90 (noventa) países. Tem como objetivo principal a implementação do terceiro objetivo da Convenção sobre a Diversidade Biológica, qual seja: garantir efetividade de uma repartição justa e objetiva dos benefícios do acesso aos recursos genéticos e conhecimentos tradicionais associados.

15 ORGANIZAÇÃO DAS NAÇÕES UNIDAS. CONVENÇÃO SOBRE A DIVERSIDADE BIOLÓGICA. Disponível em <http://www.onu.org.br/rio20/img/2012/01/cdb_ptbr.pdf.> Acesso em: 20.07.2012.

${ }^{16}$ Art. 15 da Convenção sobre a Diversidade Biológica.

17 NOTÍCIA PROTOCOLO DE NAGOYA. Disponível em http://www.ecodesenvolvimento.org.br/posts/2011/fevereiro/brasil-ratifica-protocolode-nagoya-sobre-acesso-e. Acesso em: 04.05.2015 
As normas internacionais acima mencionadas apresentam problemas em relação ao que visam proteger, ao disporem sobre a repartição de benefícios os tratados internacionais protegem apenas o aspecto econômico do conhecimento, em uma visão de natureza-objeto, tratando-o como elemento externo e como bem mercantil, deste modo os conhecimentos tradicionais também são tratados como objeto de finanças. $\mathrm{O}$ Tratado Internacional acaba por desproteger, o que visava proteger, pois não houve a incorporação das visões e cosmovisões sobre a natureza dos grupos sociais envolvidos e sem a participação dos mesmos, especialmente a Convenção sobre a Diversidade Biológica e o Protocolo de Nagoya (SHIRAISHI NETO, 2014).

Outra situação agravante é que este direito previsto na Convenção sobre a Diversidade Biológica (CDB) e no Protocolo de Nagoya são criados distantes da categoria 'lugar', pois são elaborados hierarquicamente distantes das realidades locais, neste sentido, reflete Shiraishi Neto (2014, p.308):

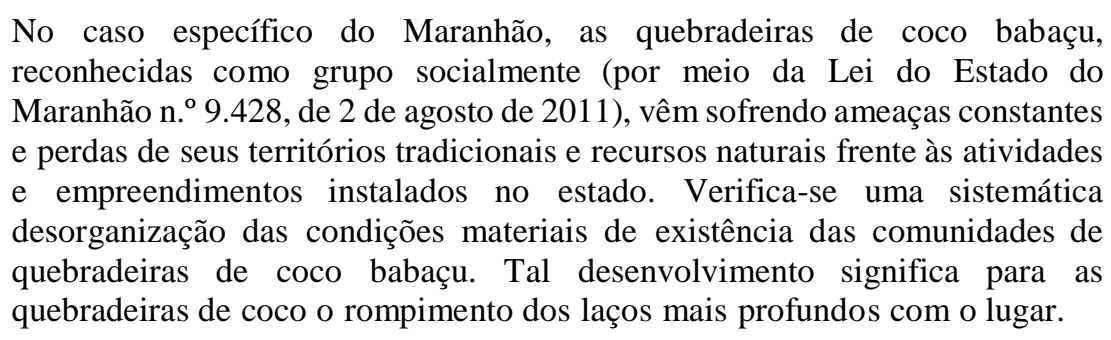

Em pesquisa feita pelo autor com o grupo social "as quebradeiras de coco babaçu" pode-se constatar que apesar de terem discutido sobre a legislação a respeito do acesso aos seus conhecimentos tradicionais associados à biodiversidade e visualizado a questão como "novos direitos", que estavam surgindo a época da subscrição do contrato de repartição de benefícios com a Natura em $2007^{18}$, sequer estavam informadas da existência das normas internacionais e muito menos convidadas a participar de sua elaboração (MACIEL, 2012).

Assim, o direito mediante dispositivos jurídicos internacionais permitiu que o conhecimento tradicional ingressasse no campo econômico a ser regulado pelo instrumento jurídico do contrato, enfatizando a visão natureza-objeto típica da Modernidade.

\footnotetext{
${ }^{18}$ Constatação decorrente da pesquisa de campo na dissertação de Mestrado de Maciel (2012):"As quebradeiras de coco babaçu e o mercado: dilema entre a proteção dos conhecimentos tradicionais e a sujeição jurídica.
} 
O direito desvinculou a questão do acesso aos conhecimentos tradicionais com a necessidade que os grupos sociais têm de que seja garantido aos mesmos, o acesso e uso dos seus territórios, ou seja, é possível a apropriação econômica dos conhecimentos, sem que o Estado garanta os territórios tradicionais para o exercício dos direitos alusivos à preservação dos conhecimentos tradicionais.

As normas internacionais ao tentarem proteger os saberes tradicionais por sua visão compartimentada e desenvolvimentistas podem acabar por desprotegê-los de outros cenários mais graves ligados à flexibilização dos territórios tradicionais e da mudança legislativa brasileira que "desburocratizou" e "facilitou" ainda mais do que os Tratados, o acesso aos conhecimentos e a utilização do patrimônio genético por indústrias farmacêuticas, empresas de biotecnologia e entidades de pesquisa.

\section{A REGULAÇÃO DOS CONHECIMENTOS TRADICIONAIS DIANTE DO ESTADO DE CRISE: A LEI N. ${ }^{\circ} 13.123 / 2015$ EM FACE DOS TRATADOS INTERNACIONAIS}

O Estado de crise analisados no primeiro capítulo possibilita e estimula a “desregulamentação", “flexibilização", "terceirização", “desburocratização” exatamente por este processo de liberalização econômica e enfraquecimento do poder do Estado que o Governo Federal promulgou a Lei n. 13.123/2015. A norma em análise sofreu influências da globalização do direito, exposta no capítulo anterior, mas chegou a ultrapassar os limites dos tratados internacionais e acabou por aprofundar a mercantilização dos conhecimentos tradicionais e instrumentalizar o acesso ao patrimônio genético e aos conhecimentos associados à biodiversidade.

A norma em análise surgiu em substituição a Medida Provisória 2.186-16/2001 editada as pressas, em razão do contrato entre a Organização a Bioamazônia e a empresa multinacional Novartis, do campo farmacêutico, com sede na Suíça. O Acordo com a Novartis previu a exploração de cerca de mil microorganismo da Amazônia brasileira pela multinacional, que seria proprietária exclusiva dos direitos de patentes e propriedade intelectual advindas a partir da utilização dos recursos genéticos brasileiros (DOURADO, 2010, p. 63).

A Medida Provisória foi considerada por membros do Congresso Nacional, um segundo estudo de exposição de motivos de Távora (2015) como "rígida", "burocrática" e "restritiva" as potencialidades do Brasil que passou a ser visto como um país que 
dificultava a utilização de sua biodiversidade, a norma anterior foi tida como "entrave" a evolução da biotecnologia nacional, uma das barreiras era a exigência de um contrato de utilização de Utilização do patrimônio genético e um Contrato de Repartição de Benefícios. Afinal, como repartir benefícios sem ter certeza de que o produto seria economicamente viável ou se traria lucros às empresas?

No entanto, a novel legislação ao fortalecer os interesses do mercado convertendo o patrimônio genético dos grupos como bem público, restringindo a repartição de benefícios aos ganhos obtidos de um produto acabado, regrando formas de repartição não-monetária de benefícios, entre outras mudanças, a nova norma flexibilizou direitos dos povos indígenas e comunidades tradicionais previstos nos tratados internacionais, visto no capítulo anterior: CDB e Protocolo de Nagoya.

As normas internacionais previram alguns direitos aos povos indígenas e comunidades tradicionais, os principais foram: Direito a manter o conhecimento tradicional, inovações e práticas das comunidades locais e populações indígenas; Direito a manter o estilo de vida tradicional relevante à conservação e à utilização sustentável da diversidade; Direito à aprovação e a participação dos detentores desses conhecimentos com respeito à suas práticas; Direito a repartição equitativa dos benefícios oriundos da utilização desse conhecimento, inovações e práticas; ${ }^{19}$ Direito a conservação da diversidade biológica, a utilização sustentável de seus componentes e a repartição justa e equitativa dos benefícios derivados da utilização dos recursos genéticos; (Art. $1^{\circ}$ da CDB); Direito de proteção e de utilização costumeira de recursos biológicos de acordo com as práticas culturais tradicionais compatíveis com as exigências de conservação ou utilização sustentável; (Alínea “c”, do art. 10 da CDB); Direito dos povos e comunidades tradicionais e agricultores familiares ao consentimento prévio fundamentado e por extensão ao dissenso ao acesso; (Artigo 15);

A Lei 13.123/2015 flexibilizou alguns destes direitos. Primeiramente, não estabelece explicitamente o direito do povo ou grupo tradicional de aprovação ou não do acesso ao patrimônio genético e aos conhecimentos tradicionais, pois ao transformar em domínio público passou legitimar a interferência direta do Estado na autorização do acesso através do CGEN - Conselho de Gestão do Patrimônio Genético. Um conceito muito caro para os grupos de consentimento prévio fundamentado previsto na CDB fora

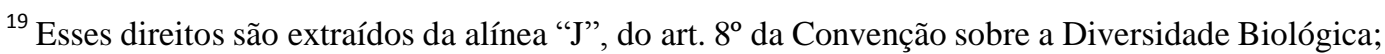


convertido pela Lei em "assinatura de termo de consentimento prévio", "registro audiovisual", "parecer do órgão competente" e "adesão via protocolo comunitário".

A Lei 13.123/2015 reduziu o conceito de repartição justa e equitativa dos benefícios decorrentes da utilização de recursos genéticos para o conceito de repartição limitada "à exploração econômica de produto acabado ou material reprodutivo oriundo de acesso ao patrimônio genético ou ao conhecimento tradicional associado".

Com a novel legislação à repartição justa e equitativa dos benefícios derivados da exploração econômica de produto acabado ou material reprodutivo oriundo de acesso ao patrimônio genético ou ao conhecimento tradicional associado. Este aspecto diverge do Protocolo de Nagoya que dispõe sobre a repartição justa e equitativa de benefícios decorrente da utilização de recursos genéticos, bem como aplicações subsequentes e comercialização, não restringindo a repartição apenas de produto acabado ou material reprodutivo.

A proteção jurídica dos conhecimentos tradicionais concebida pelo Protocolo denota ser mais ampla, ao prever que a utilização do recurso genético já é de per si passível de repartição justa e equitativa ${ }^{20}$.

A nova Lei concebe o acesso ao patrimônio genético como uma informação de bem de uso comum do povo ( $\operatorname{art} .1^{\circ}$, inciso II), diferentemente do Protocolo de Nagoya, que, em consonância com a Convenção sobre a Diversidade Biológica entende e reconhece que as comunidades indígenas e locais são os detentores dos recursos genéticos. A Lei 13.123/2015 utiliza o termo "detentores", quando se reporta ao conhecimento tradicional associado, este sim, a Lei reconhece como pertencente às comunidades indígenas e locais, contudo, quando versa sobre a isenção de obrigação de repartição de benefícios para microempresas e as empresas de pequeno porte, os microempreendedores individuais e aos agricultores tradicionais e suas cooperativas ( $\operatorname{art.17}, \S 5^{\circ}$, incisos I e II), nestas hipóteses de acesso, a norma remete a contrapartida ao Fundo Nacional de Repartição de Benefícios - FNRB.

\footnotetext{
${ }^{20}$ Exemplificando, um caso concreto de acesso ao conhecimento tradicional associado ao patrimônio genético pertencente às quebradeiras de coco pela empresa a Natura Cosméticos alusivo a farinha de mesocarpo babaçu que viria a ser transformada em cosméticos, pela nova legislação a utilização da farinha e a pesquisa nela efetuadas não poderia haver repartição de benefícios, apenas quando houvesse a exploração econômica do produto acabado, no caso os cosmético é que poderia haver repartição de benefícios. Para maiores informações ver dissertação de mestrado de Luciano Moura Maciel, citada no texto e referenciada na bibliografia.
} 
A norma prevê a possibilidade de regularização do usuário que realizou atividades de acesso aos conhecimentos tradicionais em desacordo com a legislação vigente entre 30 de junho de 2000 e a data em vigor da lei. Assim como, a lei previu uma remissão de indenizações civis relacionadas ao patrimônio genético ou conhecimento tradicional associado das quais a União é credora, estabelecendo-se, assim, uma renúncia fiscal em favor de quem acessou indevidamente os conhecimentos tradicionais.

Outro ponto extremamente relevante é que só haverá necessidade de um acordo de repartição de benefícios quando se chega efetivamente a um produto ou material reprodutivo comercializável e não mais quando houver apenas perspectiva de comercialização, e por fim, são dispensados da celebração de tal acordo de repartição de benefícios daqueles que optarem por depositar os benefícios monetários diretamente no Fundo Nacional de Repartição de Benefícios. ${ }^{21}$

A Lei 13.123/2015 prevê formas de repartição de benefício não monetárias, como troca de informações, de tecnologia. Em outras palavras, os ganhos monetários pelas indústrias de cosméticos e empresas de biotecnologia são monetários, mas a repartição de benefícios pode ser não-monetária, este mecanismos jurídico é que denomino de "aprofundamento da mercantilização dos conhecimentos tradicionais", a própria conceituação da norma da categoria conhecimentos tradicionais é muito limitada: “informação ou prática de população indígena, comunidade tradicional ou agricultor tradicional sobre as propriedades ou usos diretos ou indiretos associada ao patrimônio genético" (art. 2º, inciso II, da Lei 13.123/2015).

A conceituação legal de conhecimentos tradicionais não reflete a abrangência teórica do conceito, assim como, a complexidade e a importância da categoria jurídica para a reprodução do modo de vida dos povos indígenas, comunidades tradicionais e agricultores tradicionais. Dourado (2014, p. 17) em profundo estudo sobre o tema decorrente de tese de doutorado conceituou conhecimentos tradicionais:

Os conhecimentos tradicionais estão referidos às línguas, a técnicas de artesanato, ao conhecimento sobre o ciclo das plantas e sobre os

21 O Fundo Nacional para Repartição de Benefícios - FNRB possui um capítulo próprio na Lei 13.123/2015. Possui natureza financeira vinculada ao Ministério do Meio Ambiente com o objetivo de valorizar o patrimônio genético e os conhecimentos tradicionais associados e promover o seu uso de forma sustentável. Constituem receitas do Fundo: a) as doações; b) dotações da lei orçamentária anual; c) valores arrecadados com o pagamento de multas administrativas pelo descumprimento da Lei 13.123/2015; d) recursos financeiros de origem externa decorrente de contrato, acordos ou convênios; e) contribuições feitas por usuários do patrimônio Genético. 


\begin{abstract}
ecossistemas, à biodiversidade e ao manejo de espécies, às propriedades medicinais de substâncias naturais e aos seus modos de preparo, comumente ligados aos saberes sobrenaturais que auxiliam na cura. Os conhecimentos tradicionais também estão nas práticas agrícolas, no cuidado com a roça, no melhoramento e na domesticação de variedades locais e

no controle biológico de pragas. São também chamados de conhecimentos tradicionais os saberes referidos aos rituais, às narrativas míticas, aos cantos e danças, aos lugares sagrados, aos grafismos, à culinária e aos modos de fazer instrumentos e utensílios. Consideram-se ainda conhecimentos tradicionais aqueles que definem a forma de organização social interna dessas comunidades.
\end{abstract}

A norma jurídica precisa redimensionar o conceito de conhecimentos tradicionais para considerar sua abrangência e complexidade, pois não poderá haver proteção dos conhecimentos tradicionais na dimensão econômica dos tratados e no âmbito liberalfinanceiro em prol de indústrias da Lei 13.123/2015, que, inclusive, criou uma categoria de conhecimentos tradicionais denominada de "origem não identificável”, em que “não há a possibilidade de vincular a sua origem a, pelo menos, uma população indígena, comunidade tradicional ou agricultor tradicional" (art. $2^{\circ}$, III), desprotegendo ainda mais os conhecimentos tradicionais, podendo ao invés de pacificar conflitos agravá-los, já que todo o conhecimento possui uma origem identificável.

\title{
CONCLUSÃO
}

O artigo acabou por demonstrar que o problema dos conhecimentos tradicionais não é propriamente um problema para os povos e comunidades tradicionais que compartilham os saberes entre si, nos quintais, nas cooperativas e com pesquisadores nas comunidades. No entanto, a categoria dos conhecimentos tradicionais passou a ser um problema para o direito internacional ao se verificar o potencial destes para o desenvolvimento de pesquisas e produtos nas áreas da ciência, biotecnologia e fármacos.

O direito passou a ressignificar os conhecimentos tradicionais o que antes era visto como folclore, elementos da cultura, não eram propriedades de ninguém, como não havia a disputa pela propriedade ou posse, o direito invisibilizava os conhecimentos tradicionais como categoria jurídica relegando o debate para a antropologia.

Ao percebem o potencial econômica que podia ser convertido em bem jurídico as informações dos povos e comunidades tradicionais estes foram protegidos juridicamente devido às potencialidades econômicas dos conhecimentos tradicionais, assim, os direitos dos povos e comunidades tradicionais foram instrumentalizados para 
garantir a proteção do que pode ser mercadoria e assim garantir proteção aos conhecimentos tradicionais seria também proteger os lucros das indústrias farmacêuticas e empresas de biotecnologia.

Este processo de construção do direito sob a capa de proteção dos conhecimentos tradicionais dos povos e comunidades tradicionais, mas com o conteúdo de exploração econômica não está dissociado do "Estado em crise" e da "crise da Modernidade" refletidos no primeiro tópico, em que o Estado deixa de garantir os direitos de seus nacionais e cidadãos para se adequar as políticas neoliberais de flexibilização, privatização, desregulamentação, avanço do capital sobre a biodiversidade que pode ser facilmente observado com o modelo de regulação ambiental, em que as normas "parecem" proteger os conhecimentos tradicionais, mas não asseguram os territórios tradicionais onde os próprios saberes tradicionais são produzidos e reproduzidos, tais espaços são fundamentais para a reprodução física, social, econômica e cultural dos povos indígenas e comunidades tradicionais.

Deste modo, a Lei $13.123 / 2015$ precisa ser reformulada sob vários aspectos, principalmente quanto ao direito ao consentimento prévio fundamentado dos grupos sociais que não podem serem restringidos a meros requerimentos administrativos ou fotografias, bem como harmonizá-la com os Tratados Internacionais, como a CDB e o Protocolo de Nagoya, os quais, apesar de preverem a mercantilização dos conhecimentos tradicionais visaram assegurar alguns direitos fundamentais aos povos acessados, como a repartição justa e equitativa dos benefícios econômicos oriundos do acesso, o reconhecimento do patrimônio genético como pertencente aos povos e comunidades tradicionais, questões que sofreram sérias alterações com a nova Lei que foi capaz de aprofundar a "mercantilização dos conhecimentos tradicionais".

\section{REFERÊNCIAS BIBLIOGRAFICAS}

AGÊNCIA BRASIL EBC. Disponível em: http://agenciabrasil.ebc.com.br/economia/noticia/2016-03/governo-envia-projeto-paraencerrar-ano-com-deficit-primario-de-r-967 Acesso em 25.03.2016.

ALMEIDA, Alfredo Wagner Berno de. Conhecimentos tradicionais: "Uma nova agenda de temas e problemas. Conflitos entre o poder das normas e a força das mobilizações pelos direitos territoriais." In Cadernos de Debates Nova Cartografia Social: conhecimentos tradicionais na Pan-Amazônia/Alfredo W.B de Almeida (Orgs)... [et al]. - Manaus: Projeto Nova Cartografia Social da Amazônia / UEA Edições, 2010 
ALMEIDA, Célia. Crise Econômica, Crise do Welfare State e Reforma Sanitária. In A miragem da Pós-Modernidade democracia e políticas sociais no contexto da globalização. Silvia Gershman e Maria Lúcia Werneck Vianna (orgs) - Rio de Janeiro, FioCruz, 1997.

ARNALD, André-Jean. O direito entre a modernidade e globalização: lições de filosofia do direito e do estado. Tradução Patrice Charles Wuillaume. Rio de Janeiro: Renovar, 1999.

ASSIS, Wendell Ficher Teixeira. Do colonialismo à colonialidade: expropriação territorial na periferia do capitalismo. In Caderno CRH, Salvador, v.27, n. 72, p. 613627, 2014.

BAUMAN. Zygmunt; BORDONI, Carlo. Estado de Crise. Zahar, Rio de Janeiro, 2016.

BONAVIDES, Paulo. A crise política brasileira, Editora Forense, Rio de Janeiro, 1969; 2. ed.: 1978.

BECK, Ulrich. O que é globalização - Equívocos do globalismo. Respostas à Globalização. Tradução por André Carone. São Paulo: Paz e Terra, 1999.

BRASIL, Presidência da República. Decreto no 2.519, de 16 de março de 1998. Promulga a Convenção sobre a Diversidade Biológica, assinada no Rio de Janeiro, em 05 de julho de 1992, Brasília, 1998. <http://www.planalto.gov.br.>Acessado em 12.12.2015.

CASTELLS, Manuel. A era da informação: economia, sociedade e cultura: o poder da identidade. São Paulo: Paz e Terra, 1999. v. 2

DUSSEL, Enrique. O encobrimento do outro: A origem do mito da modernidade Conferências de Frankfurt. Tradução Jaime A. Clasen. Petrópolis, RJ: Vozes, 1993.

DOURADO, Sheilla Borges. Um panorama da legislação vigente e das propostas de normas sobre acesso e uso de recursos genéticos e de "conhecimentos tradicionais associados à biodiversidade" no Brasil. In Conhecimento tradicional e biodiversidade: normas vigentes e propostas. / Alfredo Wagner Berno de Almeida [et al]. (Orgs.) - 2. ${ }^{a}$ ed. - Manaus: ppgas-ufam / nscacestu-uea / uea Edições, 2010.

DOURADO, Sheilla Borges. Proteção Jurídica dos conhecimentos tradicionais na Pan-Amazônia: o debate dos debates. Tese (doutorado) - Universidade Federal do Pará, Programa de Pós-Graduação em Direito da Universidade Federal do Pará, 2014

FASE. Entrevista Letícia Tura. Disponível em: http://fase.org.br/pt/informese/noticias/o-sentido-da-pan-amazonia/\#sthash.YoS5jujz.dpuf. Acesso em 25.03.2016.

FRASER, Nancy. Reinventar la justicia en un mundo globalizado. NLR N. 36 , November - December 2005, 
GARAVITO, César Rodríguez. Navegando la globalización: un mapamundi para el estúdio y la práctica del derecho en América Latina. In El Derecho en América Latina: Un mapa para el pensamiento del ciclo XXI. César Rodríguez Garavito (org). $1^{\mathrm{a}}$ ed. Buenos Aires: Siglo Veintiuno Editores, 2011.

GARCÍA, Emílio Garcia. Los Derechos Humanos em su origem. M. MACEIRAS y L. MENDEZ (Coordinadores). La República Dominicana y Antón de montesinos. Salamanca: Editorial San Esteban, 2011. <http://eprints.ucm.es/12666/1/bartolome_de_las_casas.pdf $>$ Acesso em 20 de dezembro de 2015.

HOBSBAWM, Eric. Era dos Extremos: o breve século XX: 1914-1991. Tradução Marcos Santarrita. São Paulo: Companhia das Letras, 1995.

KRIMSKY, Sheldon. Science in the Private Interest: Has the Lure os Profits Corrupted Biomedical Research? Lanham: Rwman and Littlefield, 2003.

MACIEL, Luciano Moura. As quebradeiras de coco babaçu e o mercado: dilema entre a proteção dos conhecimentos tradicionais e a sujeição jurídica. Dissertação de Mestrado apresentada junto ao Programa de Pós-Graduação em Direito Ambiental pela Universidade do Estado do Amazonas, 2012.

MIGNOLO, Walter D. A colonialidade de cabo a rabo: o hemisfério ocidental no horizonte conceitual da modernidade. In A colonialidade do saber: eurocentrismo e ciências sociais. CLACSO, Consejo Latinoamericano de Ciencias Sociales, 2005. http://bibliotecavirtual.clacso.org.ar/clacso/sur-sur/20100624094657/6_Mignolo.pdf Acesso em 16 de dezembro de 2015.

ECONDESENVOLVIMENTO. NOTÍCIA PROTOCOLO DE NAGOYA. Disponível em http://www.ecodesenvolvimento.org.br/posts/2011/fevereiro/brasilratifica-protocolo-de-nagoya-sobre-acesso-e. Acesso em: 04.05.2015

ORIGEM DA PALAVRA. Disponível em http://origemdapalavra.com.br/site/palavras/crise/ Acesso em 24.03.2016.

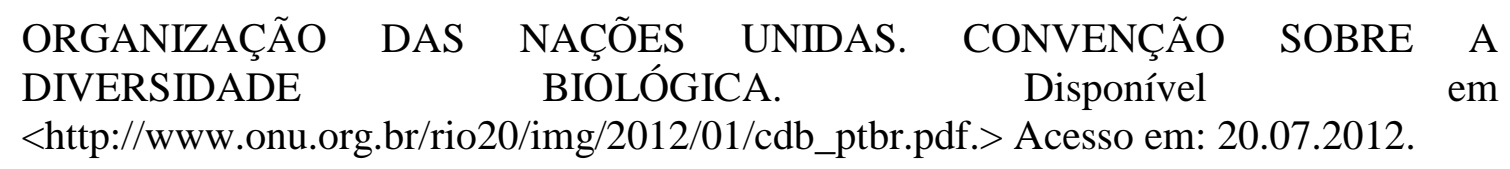

PEREIRA, LUIZ CARLOS BRESSER. A crise da América Latina: Consenso de Washington ou crise fiscal? Revista Pesquisa e Planificação Econômica, v.21, n. ${ }^{\circ}$ 01, abril, 1991. Disponível em: http://ppe.ipea.gov.br/index.php/ppe/article/viewFile/883/820. Acesso em 25.03.2016.

QUIJANO, Aníbal; WALLERSTEIN, Immanuel. Americanity as a concept, or the Americas in the modern world-system. "Americanity as a Concept, or the Americas in the Modern World. System in International Social Sciences Journal, n. ${ }^{\circ}$ 134, 1992.

QUIJANO, Aníbal. Colonialidad del poder, cultura y conocimiento en América Latina In Anuario Mariateguiano (Lima: Amauta) Vol. IX, № 9, 1997. 
QUIJANO, Aníbal. The colonial nature of power and Latin America's cultural experience. In Briceño León, Roberto and Sonntag, Heinz R. (eds.) Social Knowledge: Heritage, Challenges, Perspectives (Montreal: International Sociological Association, Pre-Congress Volumes) Vol. 5, 1998.

SANTILLI, Juliana. Socioambientalismo e Novos Direitos: Proteção Jurídica a diversidade biológica e cultural. São Paulo: Petropólis, 2005.

SANTOS, Boaventura de Souza. A gramática do tempo: para uma nova cultura política. 2.ed.- São Paulo: Cortez, 2008.

SANTOS, Boaventura de Sousa; MENESES, Maria Paula. (Orgs.) Epistemologias do Sul. São Paulo; Editora Cortez. 2009.

SHIRAISHI NETO, Joaquim. Direito ao desenvolvimento: o lugar como categoria jurídica necessária a uma sociedade plural. In Revista Jurídica da Presidência da República. Brasília v.16, 2014

SHIRAISHI NETO, Joaquim. Pachamama: estudo comparativo como instrumento de reflexão dos direitos dos povos e comunidades tradicionais no Brasil. In Revista Pensar, Fortaleza, v. 19, n.2, p. 401-426, 2014.

TÁVORA, Fernando Largares. Comentário à Lei n. 13.123 , de 20 de maio de 2015: Novo Marco Regulatório do Uso da Biodiversidade. Núcleos de Estudos e Pesquisas da Consultoria Legislativa. Senado, 2015. Disponível em www.senado.leg.br/estudos. Acesso em 18 de dezembro de 2015.

WINDHAM-BELLORD, Karen Alvarenga; COUTO, MARINA GROPEN. Protocolo de Nagoya e legislações nacionais - uma análise dos países megadiversos. In Revista Mineira de Direito Internacional e Negócios Internacionais (RMDINI), v.1, n.1, 2014. 